\title{
The Role of Transient Eddies in North Pacific Blocking Formation and Its Seasonality
}

\author{
JAEYOUNG HWANG \\ School of Earth and Environmental Sciences, Seoul National University, Seoul, South Korea \\ PATRICK MARTINEAU \\ Research Center for Advanced Science and Technology, The University of Tokyo, Tokyo, Japan \\ SEOK-WOO SON \\ School of Earth and Environmental Sciences, Seoul National University, Seoul, South Korea \\ TAKAFUMI MiYASAKA AND HISASHI NAKAMURA \\ Research Center for Advanced Science and Technology, The University of Tokyo, Tokyo, Japan
}

(Manuscript received 10 January 2020, in final form 8 May 2020)

\begin{abstract}
The mechanism of North Pacific (NP) blocking formation is investigated by conducting a reanalysis-based budget analysis of the quasigeostrophic geopotential tendency equation. It is confirmed that the amplification of NP blocking anomalies primarily results from vorticity fluxes with a minor contribution of heat fluxes. In winter, the cross-frequency vorticity fluxes, resulting from interactions between high-frequency eddies and the slowly varying background flow, dominate the blocking formation. The cross-frequency vorticity fluxes, however, become substantially weaker and comparable to the low-frequency vorticity fluxes in summer. This seasonality indicates that the mechanism of NP blocking formation varies with seasons due to the different background flow. It is further found that NP blocking formation is not sensitive to the region of formation (i.e., western vs eastern NP) nor to the type of wave breaking (i.e., cyclonic vs anticyclonic wave breaking).
\end{abstract}

\section{Introduction}

Blocking highs, as their name suggests, block the typical westerly flow in the midlatitudes (Rex 1950). The persistent blocking anomalies strongly affect surface weather, often giving rise to extreme events. For instance, in summer, blocking has been associated to consecutive heavy rainfall events such as the 2010 Pakistan flood (Hong et al. 2011; Lau and Kim 2012; Yamada et al. 2016) and serious heat wave events such as the 2003 European, 2010 Russian, and 2016 East Asian heat wave events (Black et al. 2004; Matsueda 2011; Dole et al. 2011; Schneidereit et al. 2012; Schaller et al. 2018; Yeh et al. 2018). In winter, blocking has been associated with cold surges in various regions (Trigo et al. 2004; Takaya and Nakamura 2005a,b; Park et al. 2011; Jensen 2015; Ma and Zhu 2019). Blocking is also known to substantially affect air quality by enhancing

Corresponding author: Seok-Woo Son, seokwooson@snu.ac.kr the accumulation of atmospheric pollutants such as surface ozone and particulate matters (Gangoiti et al. 2002; Czernecki et al. 2017). Given these impacts, the characteristics of blocking highs and their future changes have recently been extensively examined (e.g., Woollings et al. 2018). The dynamics of blocking formation and maintenance, however, are not fully understood yet. The lack of consensus on a comprehensive blocking theory (Woollings et al. 2018) warrants a more in-depth analysis of blocking dynamics.

Because blocking highs typically occur in the vicinity of the jet exit and storm-track regions, their formation and maintenance have been often linked to synoptic disturbances (Berggren et al. 1949). The role of highfrequency transient eddies, essentially those composed of migratory cyclones and anticyclones, has been particularly highlighted in many studies (Shutts 1983; Holopainen and Fortelius 1987; Mullen 1987). Among others, explosive cyclones are shown to play an important role in blocking formation (Colucci 1985, 1987; 
Tsou and Smith 1990; Nakamura and Huang 2018). Several studies have also reported that the interaction between synoptic-scale and planetary-scale waves is a key factor in blocking formation (Colucci 1985, 1987; Tsou and Smith 1990; Tracton 1990; Lupo and Smith 1995; Luo 2000). Nakamura et al. (1997) pointed out that blocking formation in the North Pacific (NP) may differ from that in the Euro-Atlantic sector. They indicated that while the NP blockings rely on synoptic-scale transient eddy forcing, the Euro-Atlantic blockings are driven by the propagation of quasi-stationary waves.

Most of the aforementioned studies have focused on wintertime blocking, but summertime blocking highs have been also investigated. Nakamura and Fukamachi (2004) reported that blocking formation over the Okhotsk region in the warm season has complex dynamics. While the transient eddy forcing is responsible for the Okhotsk blocking formation in May, the quasi-stationary Rossby wave trains lead to the onset of Okhotsk blockings in July. Drouard and Woollings (2018) also demonstrated that both high- and low-frequency eddies contribute to the formation of summer blocking highs in southern central Europe but low-frequency eddies are the primary forcing of the blocking onset and maintenance in western Russia.

With the goal of improving our understanding of blocking dynamics, this study reexamines the formation of NP blocking with an emphasis on their seasonality. In particular, the role of transient eddies is assessed by solving the quasigeostrophic $(\mathrm{QG})$ geopotential tendency equation by partitioning vorticity fluxes into their highand low-frequency components. Unlike the previous studies that have analyzed the blocking formation using the barotropic vorticity equation (Nakamura et al. 1997; Cash and Lee 2000; Nakamura and Fukamachi 2004), the baroclinic equation is considered.

Several of the aforementioned studies have described blocking dynamics in the time-mean sense (Shutts 1983; Holopainen and Fortelius 1987; Mullen 1987) and focused on the mechanism(s) responsible for blocking maintenance rather than blocking formation. Cash and Lee (2000), however, pointed out that the analysis of the time-averaged vorticity budget overemphasizes the contribution of high-frequency eddies, suggesting that it is more appropriate to investigate the temporal evolution of blocking to isolate the mechanisms of blocking onset, maintenance, and decay. Following their suggestion and focusing on blocking formation, all analyses in this study are carried out using 6-hourly data from $48 \mathrm{~h}$ before to the onset (or peak) of blocking highs. The winter [December-February (DJF)] and summer seasons [June-August (JJA)] are considered separately. The dependence of blocking formation mechanism on their occurrence region, whether occurring in the eastern or western North Pacific, and on the type of Rossby wave breaking are also assessed.

The paper is organized as follows. Section 2 describes the data, blocking detection algorithm, and quasigeostrophic geopotential tendency equation. In sections $3 \mathrm{a}$ and 3b, the 40-yr climatology of NP blocking highs and the composite geopotential tendency budget are documented. The role of transient eddies is then assessed and contrasted between the winter and summer seasons in section 3c, and dependence of formation dynamics on blocking location and type of Rossby wave breaking is discussed in section 3d. Finally, our findings are summarized and discussed in section 4 .

\section{Data and methods}

\section{a. Data}

In this study, 6-hourly data from the European Centre for Medium-Range Weather Forecasts interim reanalysis (ERA-Interim; Dee et al. 2011) are used to detect and analyze NP blocking highs for the period of January 1979 to December 2018. The 500-hPa geopotential height (Z500) field is utilized for the blocking detection. Horizontal wind $(u, v)$, relative vorticity $(\zeta)$, and temperature $(T)$ are used on 13 pressure levels from 1000 to $50 \mathrm{hPa}$ to evaluate the geopotential height tendency. To identify Rossby wave breaking (RWB) events, the potential temperature at $2 \mathrm{PVU}\left(1 \mathrm{PVU}=10^{-6} \mathrm{~K} \mathrm{~kg}^{-1} \mathrm{~m}^{2} \mathrm{~s}^{-1}\right)$ is also examined. To reduce computation time, all data used in this study are interpolated to a $2.5^{\circ}$ longitude $\times$ $2.5^{\circ}$ latitude grid. Although not shown, overall results are not sensitive to the horizontal resolution.

\section{b. Blocking index}

To identify NP blocking highs, the detection method described in Dunn-Sigouin et al. (2013) is employed. It is a hybrid blocking index that combines the two classical approaches to detect blocking highs, that is, a classification based on anomalies (e.g., Dole and Gordon 1983) and a classification based on zonal wind reversal (Tibaldi and Molteni 1990). The hybrid index was originally designed to be used with daily mean Z500. Since this study focuses on the temporal evolution of NP blockings, the detection algorithm is slightly modified for the use of 6-hourly data.

The geopotential height anomaly $\left(Z^{\prime}\right)$ is first defined as

$$
Z^{\prime}=Z-\bar{Z}-\hat{Z}
$$

where $Z$ is $Z 500$ normalized by the sine of latitude, $\bar{Z}$ is the running annual mean (i.e., averaging over 1460 time steps) of $Z$ centered on a given time step, and $\hat{Z}$ is a mean seasonal cycle of the running monthly mean (i.e., averaging over 120 time steps) of $Z-\bar{Z}$ centered on a 
given time. This is similar to the method of Sausen et al. (1995) except for the normalization (Dole and Gordon 1983) and no subtraction of time-mean $Z^{\prime}$ for the whole analysis period. Any $Z^{\prime}$ value larger than 1.3 standard deviations of the 3-month running-mean standard deviation over $30^{\circ}-90^{\circ} \mathrm{N}$ (approximately 90 th percentile of $Z^{\prime}$ ) is identified as a potential blocking anomaly. The region over which anomaly grid points are contiguously observed is defined as a potential blocking anomaly area. Then, it is verified that the anomaly area exceeds at least $2.5 \times 10^{6} \mathrm{~km}^{2}$ to keep only synoptic-scale anomalies. The persistence of the anomaly is also verified by evaluating the overlap of the anomaly area between two consecutive time steps. Specifically, a potential blocking anomaly is judged to be quasi-stationary here if $70 \%$ of the anomaly area is shared between the two consecutive time steps. After detecting persistent $Z^{\prime}$, the algorithm seeks a reversal of the meridional gradient of Z500 within a longitude band extending from $5^{\circ}$ west to $5^{\circ}$ east of the maximum $Z^{\prime}$ at each time step. The anomaly that meets all of these conditions for at least 5 consecutive days (20 time steps in this study) are finally defined as blocking high [see Dunn-Sigouin et al. (2013) for more details]. Note that if a blocking anomaly exists at time $t$ and $t+2$, but not at $t+1$, the blocking anomaly at $t+2$ is considered as a separate event. The onset and decay of blocking anomaly are defined as the first and last time steps when the above requirements are met. Although not shown, the overall results do not change when only geopotential anomalies are considered to detect blocking.

The NP blocking is defined as a blocking that undergoes a full life cycle over the North Pacific region $\left(30^{\circ}-82.5^{\circ} \mathrm{N}, 120^{\circ}-250^{\circ} \mathrm{E}\right)$. The center of a blocking event is defined as the grid point that has the largest $Z^{\prime}$ within the blocking area at the onset. Only blocking anomalies whose centers are located in the midlatitudes $\left(40^{\circ}-70^{\circ} \mathrm{N}\right)$ are considered. With this geographical constraint, a total of 84 and 66 NP blocking highs are detected in winter and summer, respectively.

\section{c. Quasigeostrophic geopotential tendency budget}

The QG geopotential tendency, hereafter simply QG tendency, is computed to evaluate the contribution of various dynamical processes to the temporal evolution of blocking highs. Under adiabatic and frictionless assumptions, the equation is written as

$$
\begin{gathered}
\left\{\frac{1}{f_{o}} \nabla^{2}+f_{o} \frac{\partial}{\partial p}\left[\frac{1}{s_{o}} \frac{p}{R}\left(\frac{p_{o}}{p}\right)^{\frac{R}{C_{p}}} \frac{\partial}{\partial p}\right]\right\} \frac{\partial \phi}{\partial t} \\
=-\nabla \cdot[\mathbf{V}(\zeta+f)]+f_{o} \frac{\partial}{\partial p}\left[\nabla \cdot\left(\frac{\mathbf{V} \theta_{d}}{s_{o}}\right)\right],
\end{gathered}
$$

where $\zeta$ and $f$, respectively, are relative and planetary vorticity, $\theta$ is potential temperature, $f_{o}$ is Coriolis parameter at $45^{\circ} \mathrm{N}, \mathbf{V}$ is the horizontal wind vector, $R$ is the gas constant of dry air $\left(287 \mathrm{~J} \mathrm{~kg}^{-1} \mathrm{~K}^{-1}\right), p_{o}$ is the reference pressure of $1000 \mathrm{hPa}, C_{p}$ is the specific heat capacity of dry air at constant pressure $\left(1004 \mathrm{~J} \mathrm{~kg}^{-1} \mathrm{~K}^{-1}\right), \nabla$ is the horizontal del operator $(\partial / \partial x, \partial / \partial y)$, and $\phi$ is the geopotential. The $\theta_{d}$ is defined as the deviation of potential temperature from the hemispheric mean $\left(\theta_{o}\right)$, and $s_{o}$ is the hemisphericmean static stability parameter $\left(s_{o} \equiv-\partial \theta_{o} / \partial p\right)$. Here the total wind is used instead of geostrophic wind. The two forcing terms, that is, the ones on the right-hand side of Eq. (2), are examined. They are the vorticity flux $\left(F^{\mathrm{vort}}\right)$ and the heat flux forcings $\left(F^{\text {heat }}\right)$. The total forcing $\left(F^{\text {total }}\right)$ is defined as the sum of $F^{\text {vort }}$ and $F^{\text {heat }}$.

The height tendency, which is assessed and shown only at $500 \mathrm{hPa}$, is obtained by inverting Eq. (2) using 6-hourly data on 13 pressure levels. The successive overrelaxation method is used in wavenumber-frequency space. For surface boundary condition, adiabatic thermodynamic equation shown in Eq. (3) (Lau and Holopainen $1984)$ is applied at lower $(1000 \mathrm{hPa})$ and upper $(50 \mathrm{hPa})$ boundaries:

$$
-\frac{p}{R}\left(\frac{p_{o}}{p}\right)^{R / C_{p}} \frac{\partial}{\partial p}\left(\frac{\partial \phi}{\partial t}\right)=-\nabla \cdot \mathbf{V} \theta_{d} .
$$

Although not shown, a sensitivity test is conducted by using a homogeneous Neumann boundary condition [e.g., $\partial / \partial p(\partial \phi / \partial t)=0$ ]. It turns out that the results at $500 \mathrm{hPa}$ are not sensitive to the choice of boundary conditions (see also Tsou and Smith 1990).

\section{d. Decomposition of high-and low-frequency eddies}

The vorticity flux forcing $\left(F^{\text {vort }}\right)$ is further decomposed into the contributions of high-frequency and lowfrequency transient eddies. The high-frequency component is obtained by applying an 8-day high-pass Lanczos filter to the wind and vorticity fields. The low-frequency component is then obtained by taking the difference between total and high-frequency components. Expanding the wind and vorticity fields of $F^{\mathrm{vort}}$ into their high- and low-frequency components, $F^{\text {vort }}$ can be decomposed as

$$
\begin{aligned}
F^{\mathrm{vort}} & =\mathrm{HH}+\mathrm{HL}+\mathrm{LL}, \\
\mathrm{HH} & =-\nabla \cdot\left(\mathbf{V}_{H} \zeta_{H}+\mathbf{V}_{H} f\right), \\
\mathrm{HL} & =-\nabla \cdot\left(\mathbf{V}_{L} \zeta_{H}+\mathbf{V}_{H} \zeta_{L}\right), \\
\mathrm{LL} & =-\nabla \cdot\left(\mathbf{V}_{L} \zeta_{L}+\mathbf{V}_{L} f\right) .
\end{aligned}
$$

Here, the subscripts $H$ and $L$ denote the high- and lowfrequency components. 

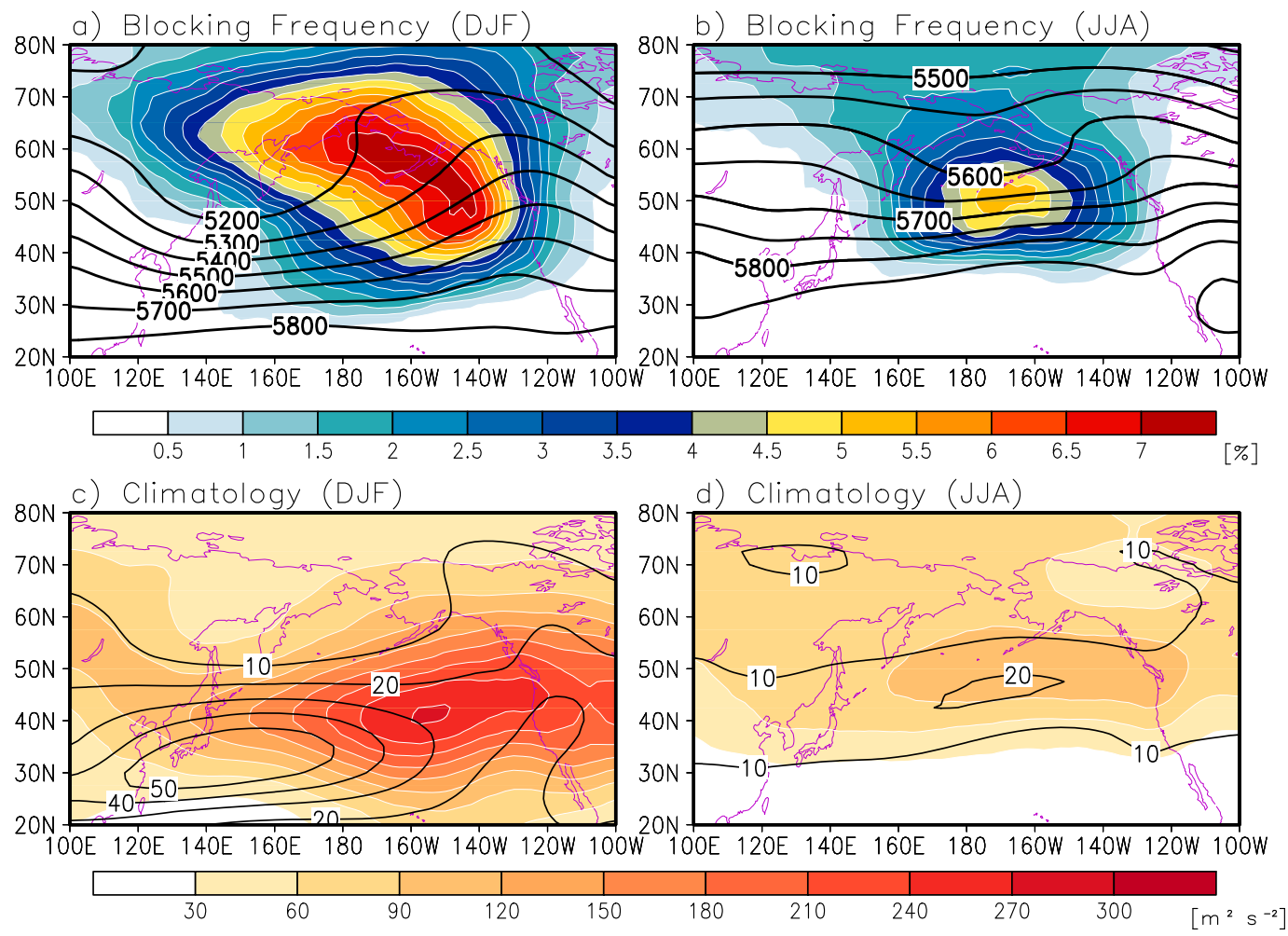

FIG. 1. (top) North Pacific blocking frequency (shading) and 500-hPa geopotential height climatology (contours). (bottom) Climatology of 300-hPa zonal wind (contours) and variance of high-pass-filtered meridional wind (shading) at $300 \mathrm{hPa}$ during (a),(c) winter and (b),(d) summer. Shading intervals are $0.5 \%$ of days in a season in the top panels and $30 \mathrm{~m}^{2} \mathrm{~s}^{-2}$ in the bottom panels. Contour intervals are $100 \mathrm{~m}$ in the top panels and $10 \mathrm{~m} \mathrm{~s}^{-1}$ in the bottom panels. Zero lines are omitted.

It is worth noting that the definition of transient vorticity flux differs from one study to another. Nakamura et al. (1997) have defined the transient vorticity flux as the convergence of relative vorticity flux terms associated with high-frequency transient eddies [see their Eq. (B1)]. In the present study, we consider absolute vorticity flux and divide the high-frequency term into $\mathrm{HH}$ and HL terms. Here, HH includes solely high-frequency transient eddies. This is similar to the definition used in many other studies (e.g., Illari 1984; Holopainen and Fortelius 1987; Mullen 1987; Drouard and Woollings 2018), except that the absolute vorticity instead of the relative vorticity is used. The cross-frequency term, HL, represents the cross-scale interaction between the high- and low-frequency components. Finally, the low-frequency term, LL, results solely from the lowfrequency (or slowly varying) components including the climatology.

\section{e. Composite method}

All blocking highs are composited with respect to each blocking center. Although the longitudinal shift in blocking highs may cause a loss of geographical identity in the composite analysis (Nakamura and Fukamachi 2004), we combine all blocking highs from western to eastern NP to better understand the general characteristics of NP blocking formation.

As emphasized in the previous studies, the blocking ridge occasionally develops rapidly (Reinhold and Pierrehumbert 1982; Dole 1986b, 1989; Alberta et al. 1991; Nakamura and Wallace 1993; Altenhoff et al. 2008). Here, we analyze the period ranging from $48 \mathrm{~h}$ before the onset to the onset of blocking highs to focus on their rapid development. Statistical significance is assessed using a bootstrap resampling method (Efron and Tibshirani 1993), where the confidence intervals are calculated by replicating the composite mean 10000 times with randomly selected data.

\section{Results}

\section{a. Blocking climatology}

The climatological NP blocking frequency in winter and summer is depicted in Figs. 1a and 1b. Here, the blocking frequency is defined as the percentage of days in a season when a grid point is considered to be a 
blocking anomaly. In winter, blocking highs occur primarily over the eastern NP, centered slightly upstream of the climatological ridge (Fig. 1a). Their frequency distribution is elongated from the northwest to the southeast around the northern flank of the jet exit (cf. Figs. 1a,c). The NP blocking highs in summer are less frequent and occur over a narrower region compared to the winter blocking highs. Their preferred region is the central NP where the jet is located (cf. Figs. 1b,d). We note that the summertime jet core's velocity is weaker than that of the wintertime jet and becomes more comparable to that of the wintertime jet exit region. Thus, winter and summer blocking occur over regions with similar basic-state velocities.

This confirms a large seasonality in blocking frequency over the NP (Barriopedro et al. 2006; DunnSigouin et al. 2013), which is also evident in the climate models (Dunn-Sigouin and Son 2013). The different geographical relationship between the jet and blocking highs in winter and summer further suggests that the blocking formation mechanism(s) may differ between the two seasons. In fact, storm activity, which is defined as the variance of 8-day high-pass-filtered meridional wind, and its relationship with the jet varies significantly with seasons. While a maximum storm activity is found downstream of the jet in winter, that in summer is present on the northern flank of the jet (Figs. 1c,d). Note that the wintertime blocking highs occur slightly to the north of the storm track in the eastern NP (cf. Figs. 1a,c). This feature has been proposed as evidence of the relationship between baroclinic eddy activity and blocking formation in winter (Berggren et al. 1949; Nakamura and Wallace 1993). The summertime blocking highs also tend to occur in the vicinity of the storm track (cf. Figs. 1b,d). However, the storm activity is substantially weaker in summer. It is thus presumed that the linkage between blocking highs and high-frequency transient eddies is rather weak in summer and that another process may regulate blocking formation.

\section{b. Temporal evolution of blocking highs}

The composited temporal evolution of winter NP blocking highs is shown in Fig. 2. Here, all variables are shown in a coordinate relative to the blocking center. A blocking high starts to develop slightly west of the climatological ridge $48 \mathrm{~h}$ before the onset. As the blocking high evolves, the ridge further amplifies while a relatively weak trough (blue contours) develops upstream of the blocking ridge (Figs. 2a,c). In agreement with the geopotential height anomaly pattern, positive geopotential height tendency is observed slightly upstream of the blocking high at $-48 \mathrm{~h}$, near its center at $-24 \mathrm{~h}$, and downstream and north of its center at the onset (Figs. 2d-f), in agreement with Dole (1986a).

The QG tendency calculated with Eq. (2) is illustrated in Figs. 2g-i. The QG tendency reasonably well reproduces the overall spatial pattern and amplitude of the observed geopotential height tendency (cf. the middle and bottom rows) although the negative tendency upstream of the blocking high is overestimated. This overestimation is likely caused by diabatic processes around the trough and/or other non-QG processes. Nevertheless, QG assumptions appear adequate to explain the key features associated with blocking formation.

The same analysis is repeated for summertime NP blocking (Fig. 3). The overall evolution is comparable to wintertime blocking. For instance, a ridge develops around the blocking center as positive geopotential height anomalies intensify. Since summertime blocking highs tend to occur in between the two climatological ridges (Fig. 1b), the blocking ridge shown in Figs. 3a-c is solely due to the anomalous circulation. Another important difference of summertime blocking highs from their wintertime counterparts is a weaker amplitude and smaller horizontal scale of positive anomalies (note that the color scale in Fig. 3 is half of that in Fig. 2). A smaller area of summer blocking highs may partly account for a narrower spatial distribution of blocking frequency in Fig. 1b. Again, these observed blocking characteristics (Figs. 3d-f) are well explained by QG dynamics (Figs. 3g-i).

The temporal evolution of geopotential height tendency during the development of winter and summer blocking highs is illustrated in Fig. 4. Each colored line shows the reanalysis tendency, QG tendency, and two contributing factors (i.e., $F^{\mathrm{vort}}$ and $F^{\text {heat }}$ ) of QG tendency averaged across the maximum positive tendency and neighboring grid points in reanalysis (dotted regions in Figs. 2d-f and $3 \mathrm{~d}-\mathrm{f}$ ). It is evident that the QG tendency captures remarkably well the wintertime tendency from the reanalysis (cf. green and black lines in Fig. 4a). The QG tendency is dominated by vorticity fluxes $\left(F^{\text {vort }}\right.$; red line in Fig. $\left.4 a\right)$ with a minor contribution of heat fluxes ( $F^{\text {heat; }}$, blue line in Fig. 4a). In summer, the QG tendency is relatively weak and steady in time, but still in a good agreement with the reanalysis. Again, vorticity fluxes dominate the blocking formation (Fig. 4b). This implies that the formation of NP blocking can be largely explained by barotropic dynamics (Tracton 1990; Tsou and Smith 1990; Lupo and Smith 1995), regardless of seasons. Although not shown, similar results are also obtained when evaluating QG tendency at $300 \mathrm{hPa}$. 

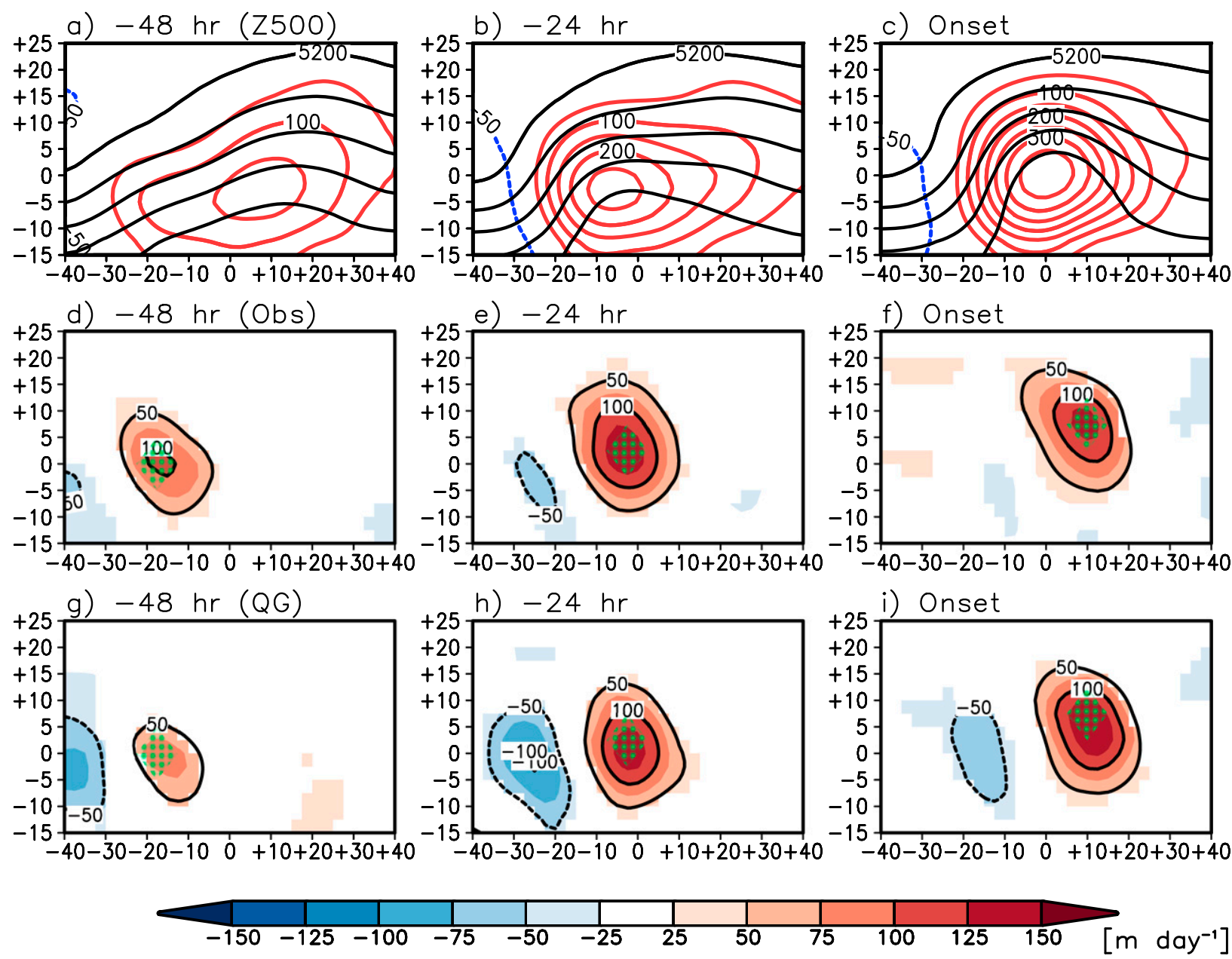

FIG. 2. Temporal evolution of (a)-(c) 500-hPa geopotential height (black contours; $100-\mathrm{m}$ intervals) and its anomaly during NP blocking highs in winter (color contours; 50-m intervals), (d)-(f) observed geopotential height tendency (black contours; $50 \mathrm{~m} \mathrm{day}^{-1}$ intervals), and (g)-(i) QG geopotential height tendency derived from the quasigeostrophic geopotential tendency equation (black contours; $50 \mathrm{~m}$ day ${ }^{-1}$ intervals). All values are shown in relative longitude-latitude coordinates with respect to blocking anomaly centers. Zero lines are omitted and statistically significant geopotential height tendencies at the $95 \%$ confidence level are shaded. Note that the shading interval $\left(25 \mathrm{~m} \mathrm{day}{ }^{-1}\right)$ in (d)-(i) is half of the contour interval. The stippled region represents the maximum height tendency of observation at each time step.

\section{c. Role of high- and low-frequency transient eddies}

Figure 5 illustrates the spatiotemporal evolution of the wintertime QG tendency forced by total vorticity fluxes and three components of vorticity fluxes in Eq. (4) (i.e., high-frequency, low-frequency, and cross-frequency vorticity fluxes). The forcing by total vorticity fluxes is quantitatively similar to the total QG tendency (Figs. 5a-c). The tendency associated with highfrequency fluxes $(\mathrm{HH})$, is weakly negative over the region where the observed tendency is positive (dotted areas; Figs. 5d-f). Although low-frequency fluxes (LL) assist the blocking formation over the $24 \mathrm{~h}$ leading to the onset, their contribution is still small (Figs. 5h,i). Compared to $\mathrm{HH}$ and LL, the cross-frequency fluxes (HL) account for a large fraction of the total height tendency (Figs. 5j-1). This result is consistent with the previous studies that have highlighted the interaction between high-frequency transients and planetary-scale waves for the development of blocking highs (Colucci 1985, 2001; Tsou and Smith 1990; Tracton 1990).

To elucidate the processes responsible for the crossfrequency term, HL is further decomposed into

$$
\begin{aligned}
\mathrm{HL} & =\mathrm{HL} 1+\mathrm{HL} 2, \\
\mathrm{HL} 1 & =-\nabla \cdot \mathbf{V}_{L} \zeta_{H}, \\
\mathrm{HL} 2 & =-\nabla \cdot \mathbf{V}_{H} \zeta_{L} .
\end{aligned}
$$

In winter, the formation of NP blocking is almost exclusively explained by the HL1 term (Figs. 6a-c). 

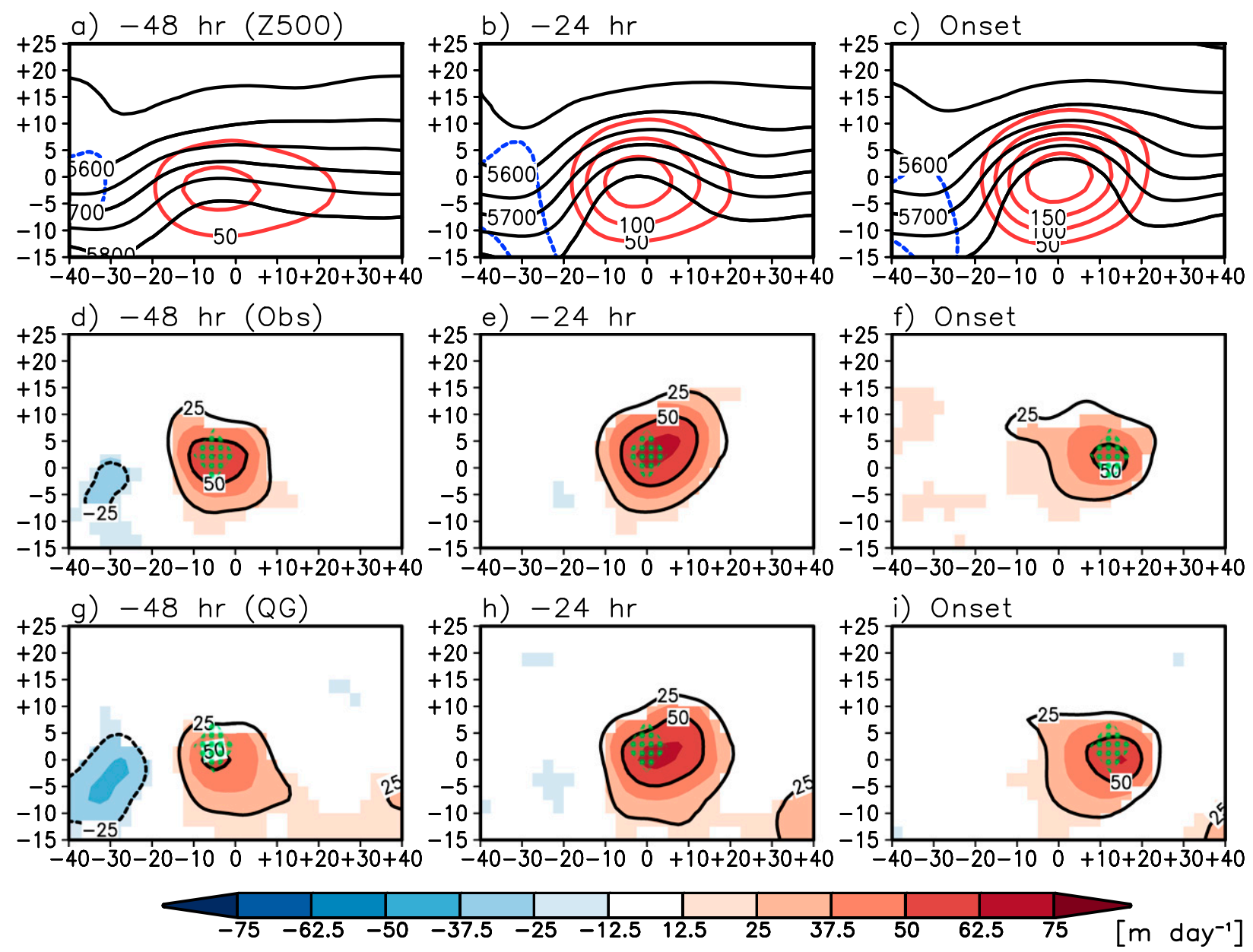

FIG. 3. As in Fig. 2, but for summer. Note the color scale is adjusted (halved) to show the weaker geopotential height tendency in summer.

The HL2 term slightly cancels the HL1 term (Figs. 6j-1). This result reaffirms that the interaction between the low-frequency background flow and high-frequency synoptic disturbances is a primary factor in the formation of NP blocking. By decomposing $\mathbf{V}_{L}$ into the climatological wind and low-frequency anomaly $\left(\mathbf{V}_{L}=\right.$ $\mathbf{V}_{\text {Clim }}+\mathbf{V}_{\text {LFa }}$ ), HL1 can be written as

$$
\begin{aligned}
\text { HL1 } & =\text { HL1c }+ \text { HL1a, } \\
\text { HL1c } & =-\nabla \cdot \mathbf{V}_{\mathrm{Clim}_{H}} \zeta_{H} \\
\text { HL1a } & =-\nabla \cdot \mathbf{V}_{\mathrm{LFa}} \zeta_{H} .
\end{aligned}
$$

It is found that a large fraction of HL1 is explained by the HL1c term (Figs. 6d-f). This is consistent with the fact that winter NP blocking typically occurs at the jet exit region where high-frequency eddies are dominant (see Figs. 1a,c).

The above result indicates that wintertime NP blocking mainly forms by flux convergence of high-frequency anticyclonic anomalies or flux divergence of highfrequency cyclonic anomalies at the climatological jet exit region. The contribution of HL1a term to blocking onset is relatively weak, but still nonnegligible (Figs. 6g-i). It implies that the low-frequency waves $\left(\mathbf{V}_{\mathrm{LFa}}\right)$ also play an important role in the development of blocking highs (see also Colucci 1987). Although not shown, the HL2 term around the onset day is almost exclusively caused by $-\nabla \cdot \mathbf{V}_{H} \zeta_{\mathrm{LFa}}$ term (see also Colucci 2001), but its magnitude is considerably weaker than that of HL1c and HL1a terms.

Figure 7 shows the same analysis for summertime NP blocking. As in winter, the QG tendency is largely explained by vorticity fluxes (Figs. $7 \mathrm{a}-\mathrm{c}$ ). The QG tendency induced by the high-frequency transients (HH) is important only upstream of blocking highs (Figs. 7d-f). At the blocking center, both low-frequency (LL; Figs. 7g-i) and cross-frequency (HL; Figs. 7j-1) terms are dominant, although the latter has a smaller spatial scale. This is in stark contrast to wintertime NP 

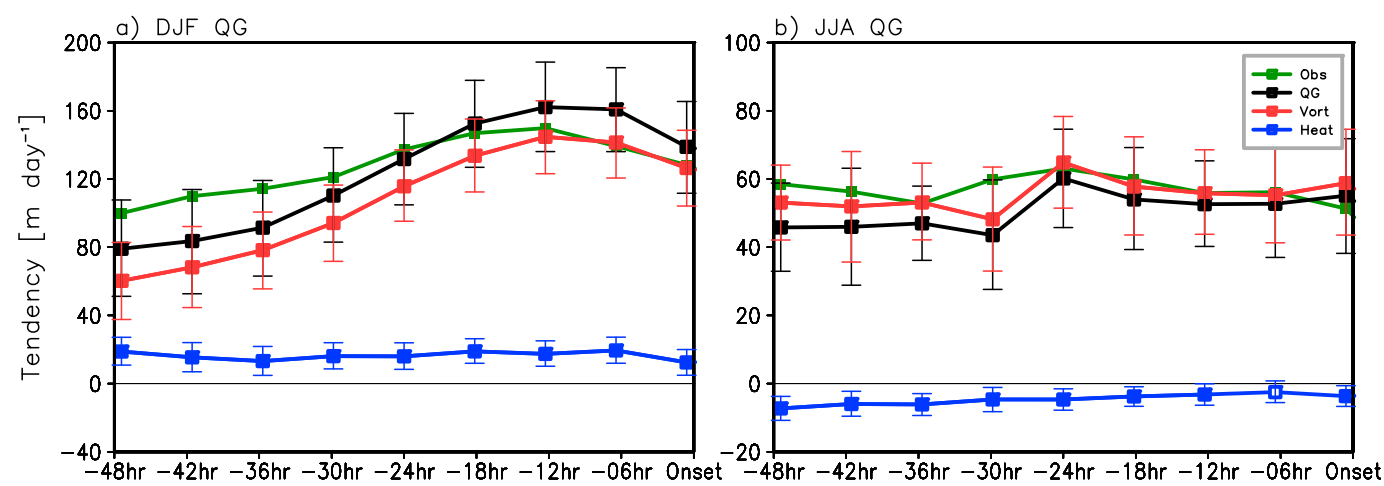

FIG. 4. Time series of geopotential height tendency at the maximum positive tendency (green dots in Figs. 2 and 3), which is present in reanalysis for (a) winter and (b) summer. Green lines show the tendency obtained from reanalysis. Black, red, and blue lines show the quasigeostrophic height tendency (QG tendency) caused by the total forcing (vorticity + heat), vorticity flux, and the heat flux, respectively. Whiskers indicate the $95 \%$ confidence intervals. Filled squares indicate the values that are significantly different from zero.

blocking, which is primarily driven by cross-frequency fluxes with a minor contribution of low-frequency fluxes (cf. Figs. 5 and 7).

The QG tendency generated by HL1, its two components (i.e., HL1c and HL1a), and HL2 terms are depicted in Fig. 8. Each term exhibits a complex spatiotemporal evolution. The positive HL tendency near the blocking center (Figs. 7j-1) is initially dominated by HL1 term (Fig. 8a) but later supported by both HL1 and HL2 terms (Figs. 8c,1). It is further found that the HL1c term persistently explains a positive tendency (Figs. 8d-f). The contribution of HL1a to blocking formation, which explains the majority of negative tendencies in HL1, is rather minor (Figs. 8g-i). This result indicates that the flux of high-frequency eddies by the climatological circulation are contributing strongly to the formation of summertime NP blocking. The tendency generated by the HL2 term, which is mostly dominated by $-\nabla \cdot \mathbf{V}_{H} \zeta_{\mathrm{LFa}}$ (not shown), contributes to a positive tendency during the onset (Figs. $8 \mathrm{j}-1$ ). But it is largely canceled out by the negative tendency of HL1.

It is important to note that the LL term in summer is comparable to that in winter (cf. Figs. $5 \mathrm{~g}-\mathrm{i}$ and $7 \mathrm{~g}-\mathrm{i}$ ). A decomposition of the LL term shows a cancelation between $-\nabla \cdot \mathbf{V}_{\mathrm{LFa}} f$ term, which forces $Z^{\prime}$ to rise upstream, and $-\nabla \cdot \mathbf{V}_{\text {Clim }} \zeta_{\mathrm{LFa}}$ term, which forces height anomalies to rise downstream (not shown). The latter, however, is larger than the former, inducing positive anomalies downstream of the blocking center. This result implies that the LL term, which is comparable to the HL term in summer, is caused by the downstream convergence of low-frequency anticyclonic anomalies at the climatological jet exit region. The above results indicate the important role of the climatological flow in HL and LL terms, which cause NP blocking highs.

Figure 9 summarizes the temporal evolution of the QG tendency term as in Fig. 4 but for individual components.
In winter (Fig. 9a), the vorticity fluxes (red) are primarily induced by the cross-frequency fluxes (HL; brown) with a relatively minor contribution from low-frequency fluxes (LL; light green). The high-frequency fluxes $(\mathrm{HH}$; light blue) act as a negative forcing, largely canceling the lowfrequency fluxes. When integrated over $48 \mathrm{~h}$ (Fig. 9g), HL, LL, and HH terms explain $86 \%, 18 \%$, and $-20 \%$ of the observed tendency. The QG tendency induced by HL1 (violet) dominates the $\mathrm{QG}$ tendency generated by vorticity fluxes (Figs. 9b,g). A further decomposition of $\mathbf{V}_{L}$ into the climatological wind and low-frequency anomaly shows that HL1c explains the majority of the HL1 tendency (over $60 \%$ ) although the forcing by low-frequency waves (HL1a) is not negligible. This indicates that the flux convergence of high-frequency anticyclonic eddies at the climatological jet-axis region, where the background flow is diffluent, is essential for blocking formation (Figs. 9c,g).

In summer (Fig. 9d), the cross-frequency vorticity fluxes (HL) are still important. This term is initially dominated by the HL1 term at $48 \mathrm{~h}$ before the onset as in winter, but later supported by both HL1 and HL2 terms from $-24 \mathrm{~h}$ to the onset (Fig. 9e). The overall magnitude of the HL1 term, however, is much smaller than that in winter (cf. Figs. 9b,e). It is also noteworthy that, unlike in winter, HL1 and HL2 terms have the same sign when integrated over $48 \mathrm{~h}$ (Fig. 9h). Most importantly, the HL term is comparable to the LL term in the course of blocking development (Fig. 9d). This result highlights the importance of the background flow in the summer blocking formation.

\section{d. Dependence on blocking location and type of Rossby wave breaking}

The possible dependence of blocking formation on the geographical location, that is, eastern versus 

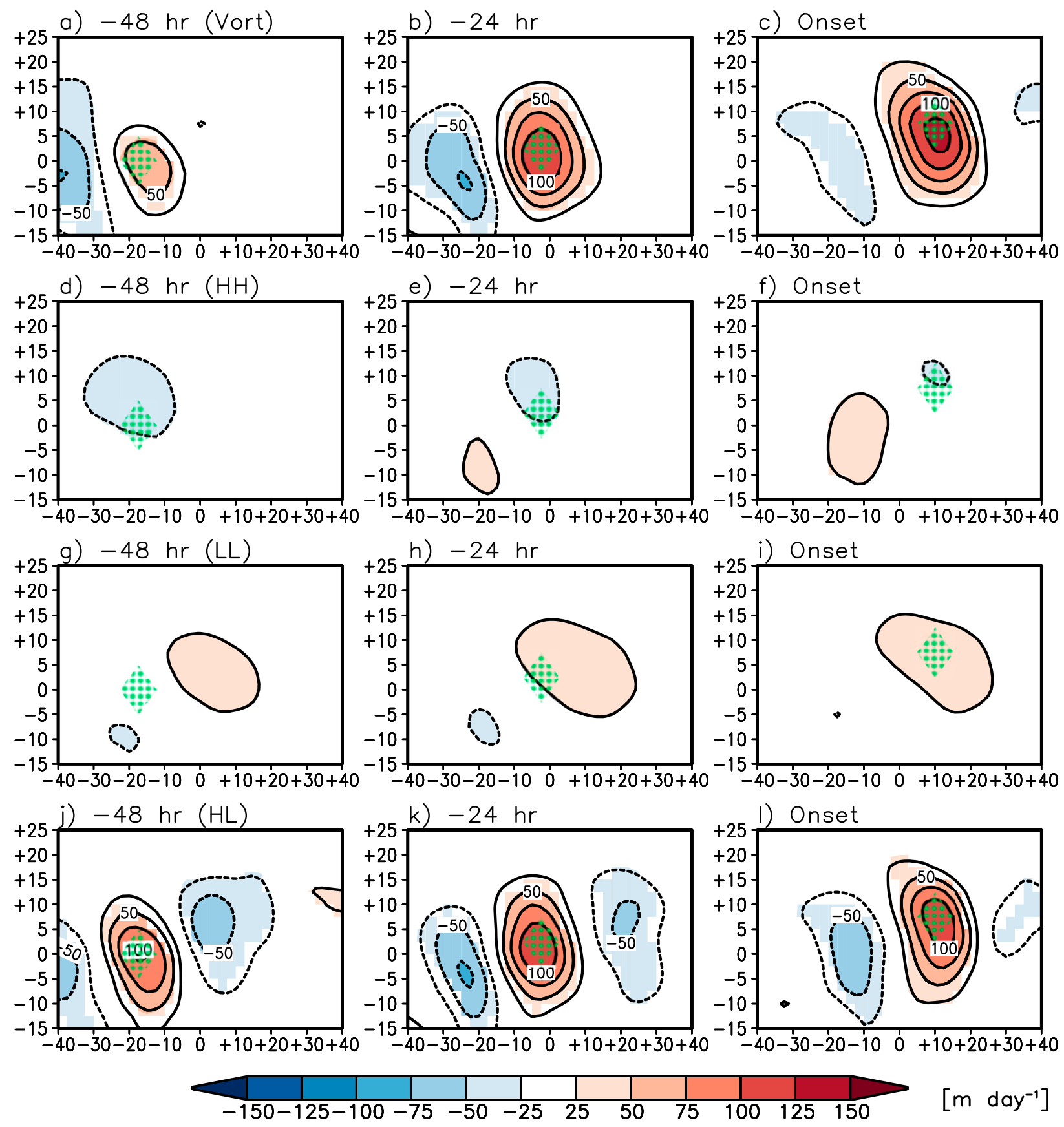

FIG. 5. Temporal evolution of geopotential height tendency forced by (a)-(c) total, (d)-(f) high-frequency, (g)-(i) low-frequency, and (j)-(1) cross-frequency vorticity fluxes before the onset of NP blocking in winter. Statistically significant values at the $95 \%$ confidence level are shaded. All values are shown with longitude-latitude coordinates relative to blocking anomaly centers. The stippled regions represent the maximum height tendency of observation at each time step (see Fig. 2).

western NP, is briefly examined. Here the eastern NP blockings include blocking highs identified over $180^{\circ}-250^{\circ} \mathrm{E}$, while the western NP blockings include blocking highs over $120^{\circ}-180^{\circ} \mathrm{E}$ (Table 1). Figures 10a and $10 \mathrm{~b}$ illustrate the relative contributions of the HL and LL terms to $F^{\text {vort }}$, which are obtained by averaging the QG tendency from $-48 \mathrm{~h}$ to the onset. The eastern NP blockings (open marks) are again mostly explained by the cross-frequency vorticity fluxes in winter (HL; $84 \%$ of events). The same is also true for most western NP blockings (filled marks, $85 \%$ of events). This indicates that the formation mechanism is 

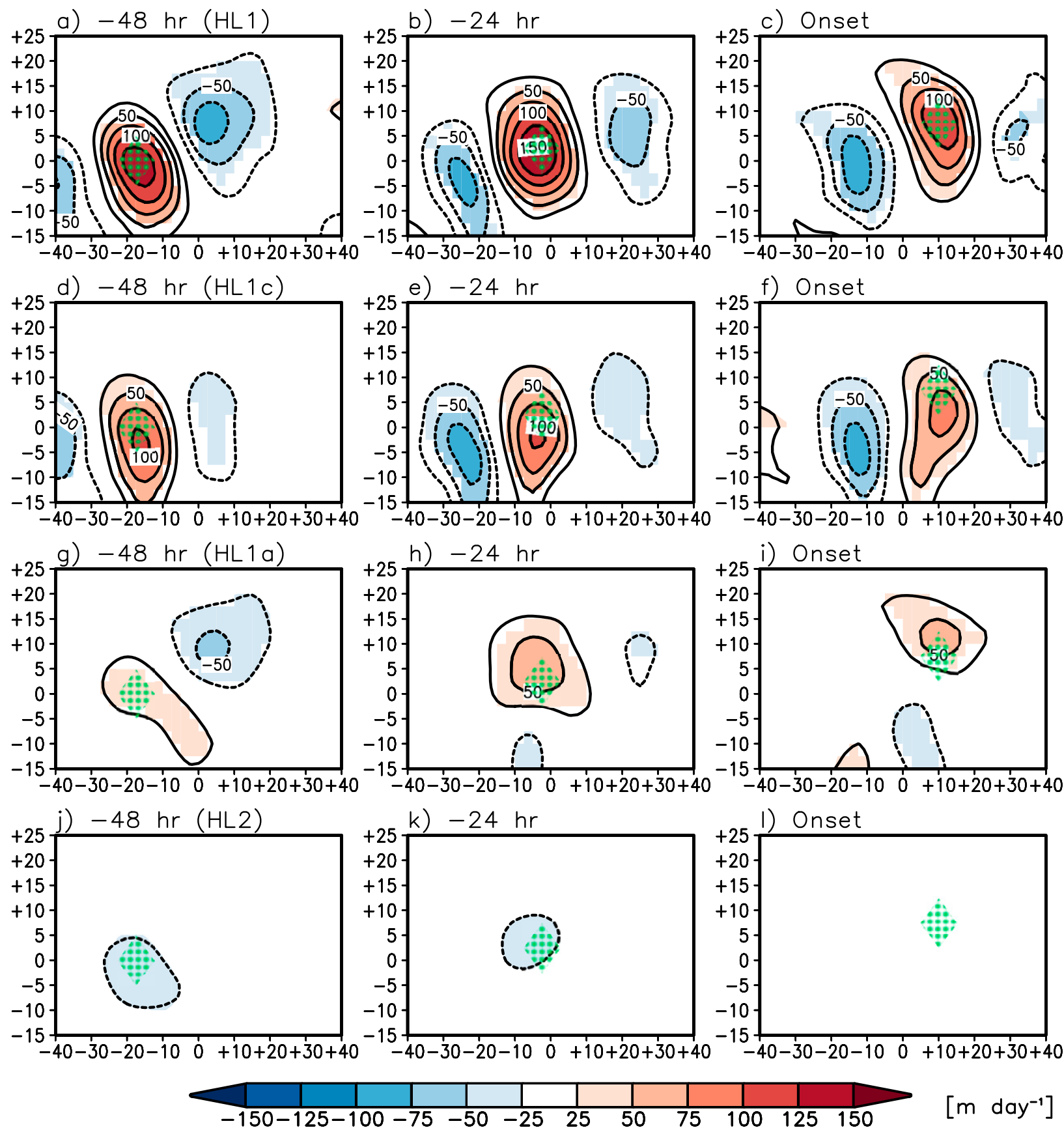

FIG. 6. Temporal evolution of quasigeostrophic geopotential height tendency forced by (a)-(c) HL1, (d)-(f) HL1c, (g)-(i) HL1a, and (j)-(1) HL2. Note that the sum of HL1c and HL1a are equivalent to HL1 but with the low-frequency term replaced by the sum of climatology $\left(-\nabla \cdot \mathbf{V}_{\mathrm{Clim}} \zeta_{H}\right)$ and low-frequency anomaly $\left(-\nabla \cdot \mathbf{V}_{\mathrm{LFa}} \zeta_{H}\right)$ during winter. Statistically significant values at the $95 \%$ confidence level are shaded. Zero lines are omitted. The stippled areas represent the maximum height tendency of reanalysis at each time step (see Fig. 2).

not strongly sensitive to the geographical location of blocking formation. In summer, the NP blocking highs are either forced by the HL and/or LL term (Fig. 10b). This indicates a larger diversity in blocking formation in summer. This result is also not sensitive to the blocking location.
Next, we explore the type of wave breaking (RWB) associated with blocking highs. The RWB type is computed as in Masato et al. (2013) with minor modifications (see appendix for the details). In winter, it is found that NP blocking highs are more frequently associated with cyclonic RWBs (circle marks) rather than anticyclonic 

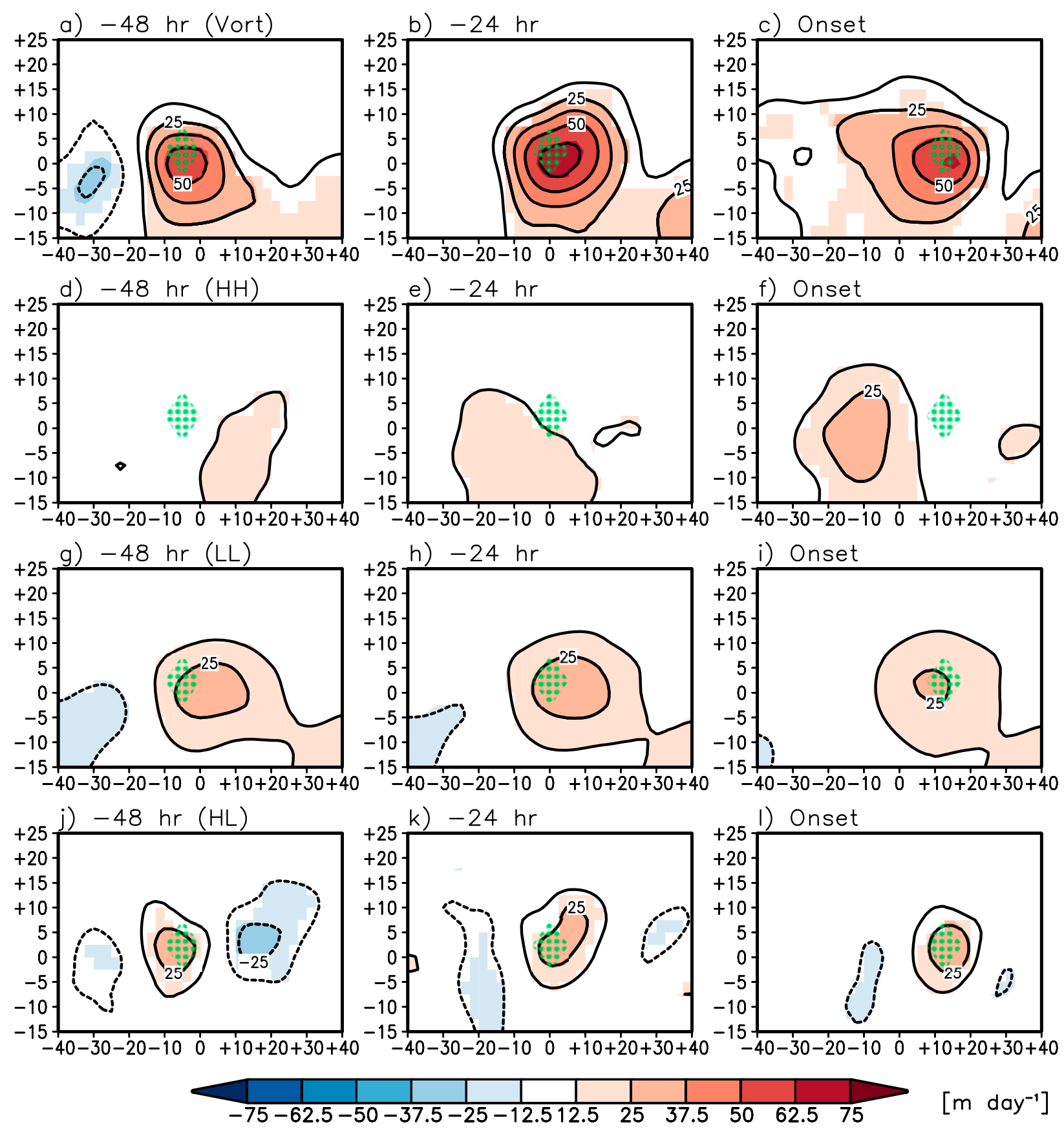

FIG. 7. As in Fig. 5, but for summer. The color scale is adjusted (halved) to show the weaker summertime tendencies.

RWBs (triangle marks; see also Table 1) as in Masato et al. (2012), and the difference between cyclonic and anticyclonic RWBs is larger for western Pacific blocking events. This result is consistent with the geographical location of blocking formation relative to the climatological jet. Note that the NP blocking highs typically form on the poleward side of the jet where the climatological shear is cyclonic (Fig. 1c). In contrast, summer blockings are often associated with anticyclonic RWB. However, it is noted that the presence or type of RWB does not appear to modulate the relative contribution of transient vorticity fluxes in blocking formation, especially during the initial development (Fig. 10).

It is noteworthy that blocking highs can also be defined as low-frequency or quasi-stationary anticyclonic anomalies (e.g., Nakamura et al. 1997). The development of the low-frequency component of the blocking events analyzed here can be evaluated by applying a 

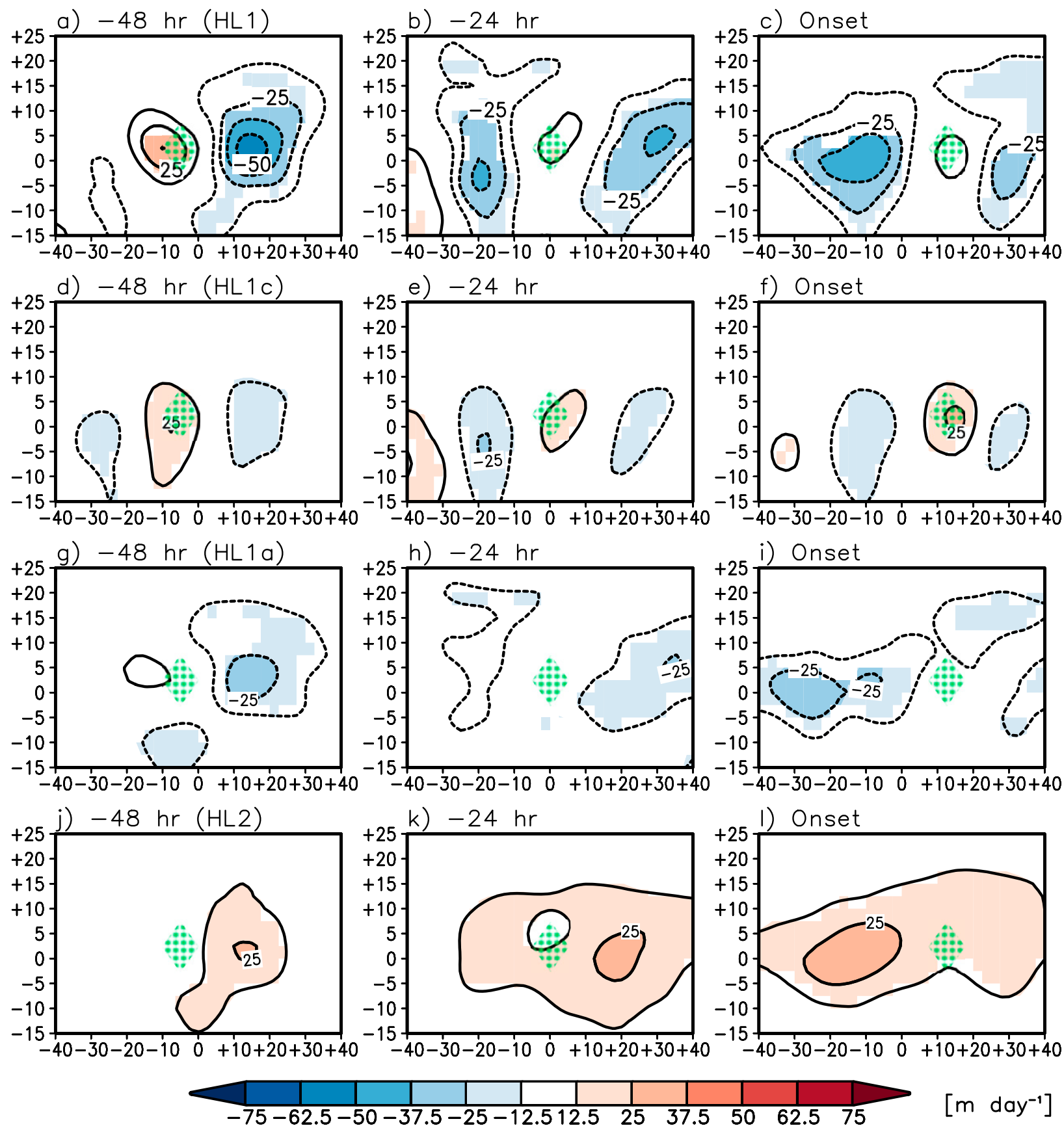

FIG. 8. As in Fig. 6, but for summer. The color scale is adjusted (halved) to show the weaker summertime tendency.

low-pass filter to Eq. (2). Figure 11 presents the lowpass-filtered blocking anomalies (cf. to Figs. 2a-c) and their tendency due to total vorticity fluxes, highfrequency (low-pass-filtered $\mathrm{HH}$ ), and low-frequency (low-pass-filtered LL) fluxes in winter (cf. to Figs. 5a-i). The contribution of low-pass-filtered cross-frequency eddy interactions, which is negligible in comparison to $\mathrm{HH}$ and LL terms, is neglected. In the absence of crossfrequency vorticity fluxes, the low-pass-filtered height tendency is dominated by low-frequency fluxes (Figs. $11 \mathrm{j}-$ 1) with a nonnegligible contribution by high-frequency fluxes (Figs. 11g-i). Note that while the low-frequency fluxes force a downstream displacement of the blocking, the high-frequency fluxes act to retard this displacement. Therefore, our analysis suggests that while the rapid development of blocking results from the interaction between the large-scale slowly evolving flow and highfrequency anticyclonic anomalies, the development of 


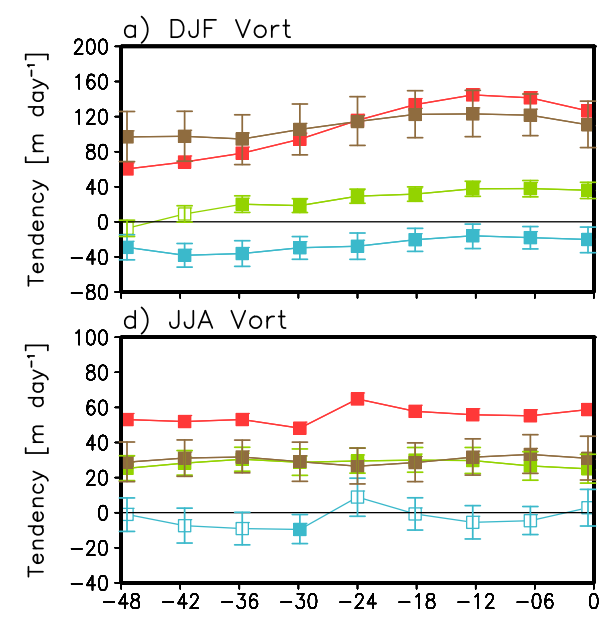

b) DJF $\mathrm{HL}$

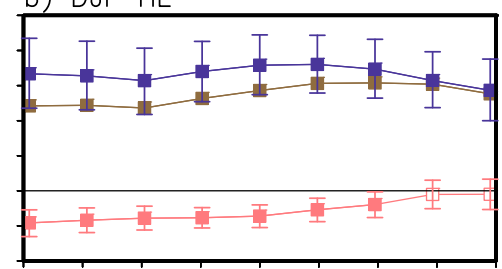

e) JJA HL

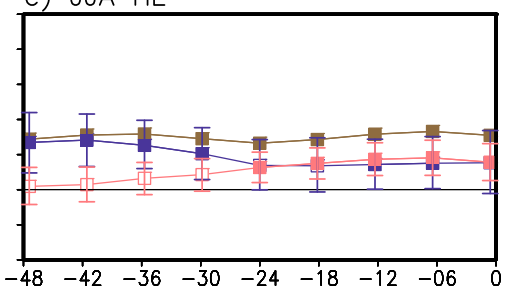

c) DJF HL1

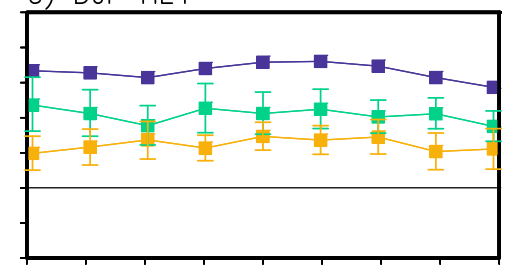

f) JJA HL1

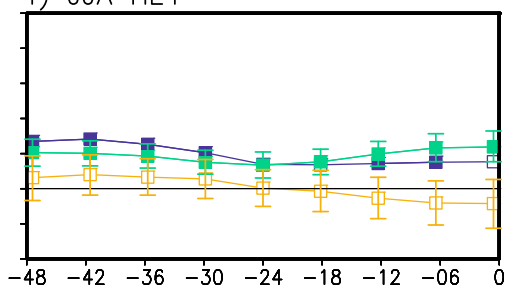

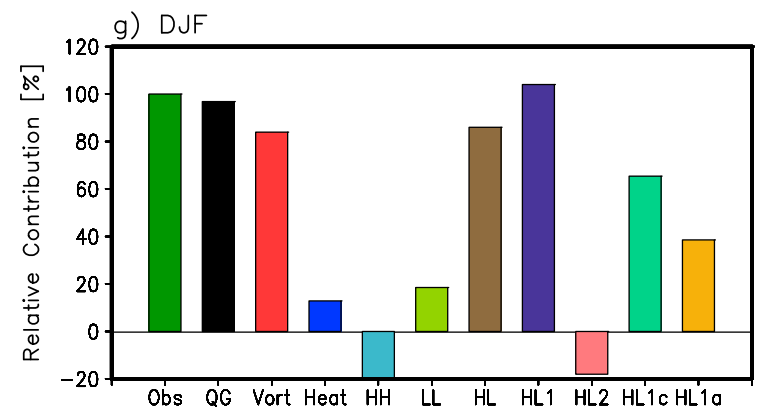
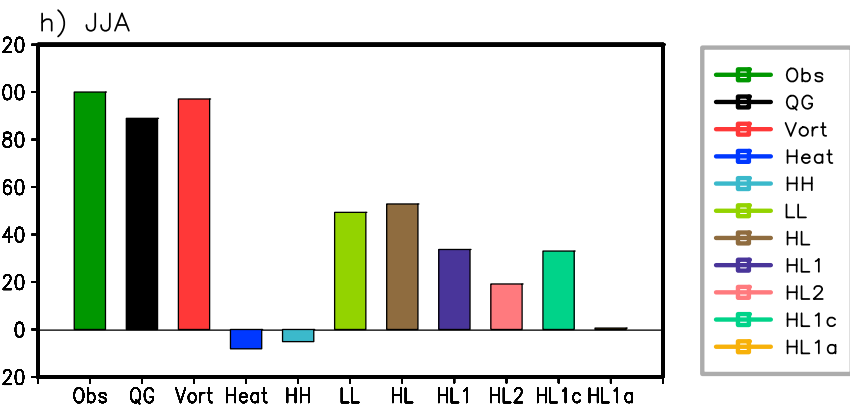

FIG. 9. (a)-(f) Time series of the observed tendencies, the QG geopotential height tendencies, and the relative contributions of various forcing terms and $(\mathrm{g}),(\mathrm{h})$ their average from $-48 \mathrm{~h}$ to the onset. The tendencies are averaged over the dotted regions shown in Figs. 5-8 for (a)-(c),(g) winter and (d)-(f),(j) summer blocking. Green denotes the reanalysis tendency. Black, red, and blue denote the QG tendency induced by the total forcing (vorticity + heat), vorticity flux, and heat flux forcing, respectively. Light blue, light green, and brown show the QG tendencies driven by high-frequency (HH), low-frequency (LL), and cross-frequency vorticity fluxes (HL), respectively. Violet, pink, emerald green, and yellow indicate the QG tendency of the HL1, HL2, HL1c, and HL1a terms, which contribute to the HL term. In (a)-(f) whiskers indicate the $95 \%$ confidence interval, and filled squares indicate the values that are significantly different from zero.

the persistent component of blocking events results primarily from low-frequency vorticity fluxes with an additional but minor contribution from high-frequency eddies.

\section{Summary and discussion}

This study investigates the formation mechanism of the North Pacific (NP) blockings and their seasonality by analyzing large number of blocking highs with an emphasis on their rapid development. In particular, the role of various dynamical processes on the development of NP blockings is quantitatively assessed by solving the quasigeostrophic $(\mathrm{QG})$ geopotential tendency equation at $500 \mathrm{hPa}$. Specifically, scale partitioning is conducted to examine the role of transient eddies in the formation of NP blockings, and its dependence on blocking location and type of Rossby wave breaking.

It is shown that QG tendency captures well the observed tendency at and downstream of the blocking center. However, nonnegligible mismatch appears upstream of the blocking ridge. This bias may result from diabatic processes that are not considered in the present

TABLE 1. Classification of North Pacific (NP) blocking highs according to the geographical location and Rossby wave breaking (RWB) type.

\begin{tabular}{|c|c|c|c|c|c|c|}
\hline & \multicolumn{3}{|c|}{ Winter } & \multicolumn{3}{|c|}{ Summer } \\
\hline & ALL & Eastern NP & Western NP & ALL & Eastern NP & Western NP \\
\hline ALL & 84 & 64 & 20 & 66 & 46 & 20 \\
\hline Cyclonic RWB & 47 & 31 & 16 & 25 & 19 & 6 \\
\hline Anticyclonic RWB & 25 & 21 & 4 & 34 & 22 & 12 \\
\hline NONE & 12 & 12 & 0 & 7 & 5 & 2 \\
\hline
\end{tabular}


a) DJF

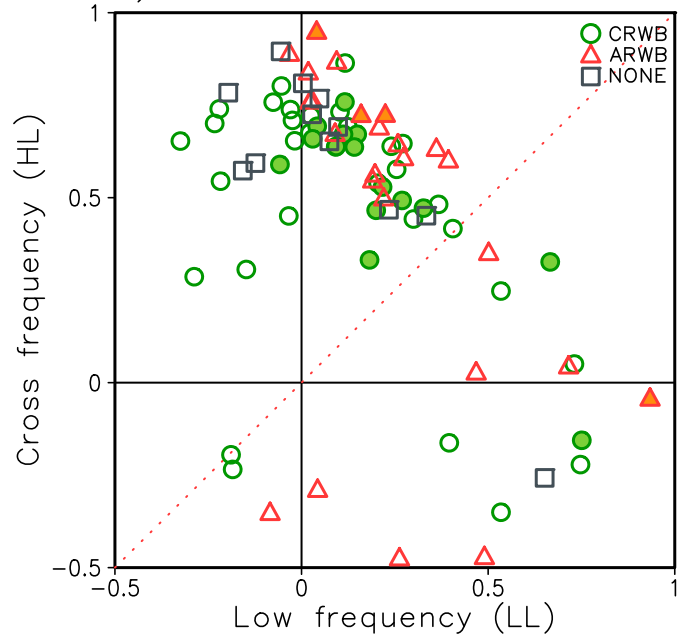

b) JJA

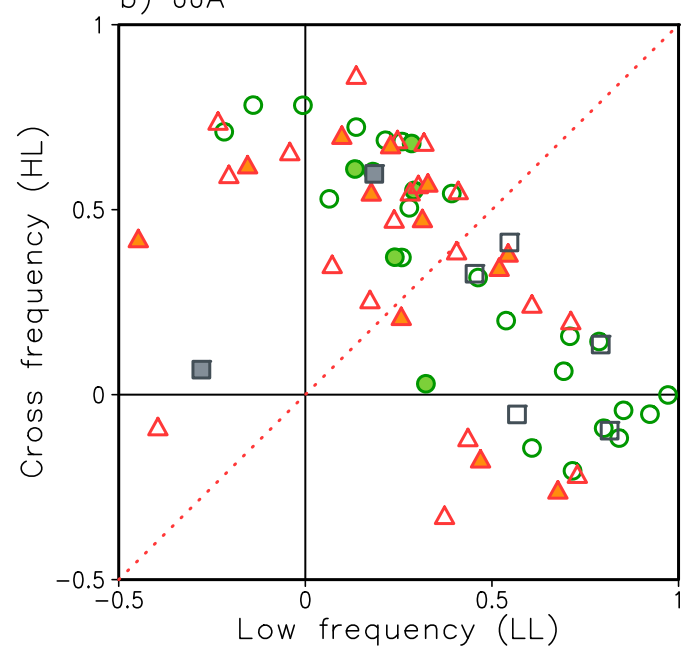

FIG. 10. Relative contributions of low-frequency $\left(\mathrm{LL} / F^{\mathrm{vort}}\right)$ and cross-frequency $\left(\mathrm{HL} / F^{\mathrm{vort}}\right)$ vorticity fluxes to NP blocking formation averaged from $-48 \mathrm{~h}$ to the onset in (a) winter and (b) summer. Circles and triangles indicate blocking highs associated with cyclonic and anticyclonic RWB, respectively. The blocking highs that are not associated with RWB are denoted with gray squares. Open and filled symbols indicate blocking highs that occur in the eastern and western North Pacific.

study. Previous studies suggested that latent heating upstream of blocking ridge may play an important role in blocking formation (Gall et al. 1979; Pfahl et al. 2015). However, we presume that diabatic processes indirectly affect the positive height tendency, which is maximized to the north of the blocking center (Dole 1986a), by enhancing the blocking anomalies via barotropic processes (Tracton 1990).

It is confirmed that the QG tendency is mostly forced by vorticity fluxes in both winter and summer. The contribution of heat fluxes is negligible, indicating that the NP blocking formation is primarily explained by barotropic processes (Tracton 1990; Tsou and Smith 1990; Lupo and Smith 1995). The role of vorticity fluxes is further explored by assessing the contributions of high-, cross-, and low-frequency transient eddies. In winter, vorticity fluxes mainly result from the crossfrequency term, which represents the interaction between high-frequency eddies and the low-frequency (mostly climatology) background flow. The convergence of anticyclonic anomalies or divergence of cyclonic anomalies at the exit of the climatological jet is a crucial factor in blocking formation. Other terms, that is, high- and low-frequency vorticity fluxes, play a rather minor role, canceling each other. The summer NP blocking, however, is influenced not only by cross-frequency interactions but also by low-frequency vorticity fluxes. The latter is comparable to the former. Again, the climatological background flow plays a crucial role.

It is also found that although small in magnitude, high-frequency vorticity fluxes contribute to increasing geopotential tendency upstream of the blocking center $24 \mathrm{~h}$ before the onset, in both winter and summer. This forcing, which is located about one-quarter wavelength upstream of the blocking ridge (Mullen 1987), acts to retard the downstream propagation of blocking anomalies, thus enhancing blocking persistence (Shutts 1983; Holopainen and Fortelius 1987). At the blocking center, high-frequency eddies tend to weaken blocking anomalies.

The budget analysis reveals that the formation mechanism of winter and summer NP blocking is somewhat different due to differences in the background flow and the climatologically weaker summertime high-frequency eddy activity. As stated above, cross-frequency vorticity fluxes, representing the interaction between high-frequency eddies and the lowfrequency background flow, dominate the winter NP blocking formation. The preferred blocking region is, in fact, found north of the jet exit region, where highfrequency eddy activity peaks, reaffirming that the proximity of a diffluent jet and high-frequency eddy activity are necessary ingredients for wintertime blocking formation. However, there appears to be greater diversity in the driving mechanism of summer NP blockings. While some blockings are strongly forced by cross-frequency vorticity flux convergence, others are forced mostly by low-frequency anomalies. It is likely the result of quasi-stationary Rossby wave trains propagating along the jet and breaking on its flanks. Those results are not sensitive to blocking location (i.e., eastern or western NP sectors) as well as the relationship to Rossby wave breaking (RWB) (i.e., cyclonic or anticyclonic). 

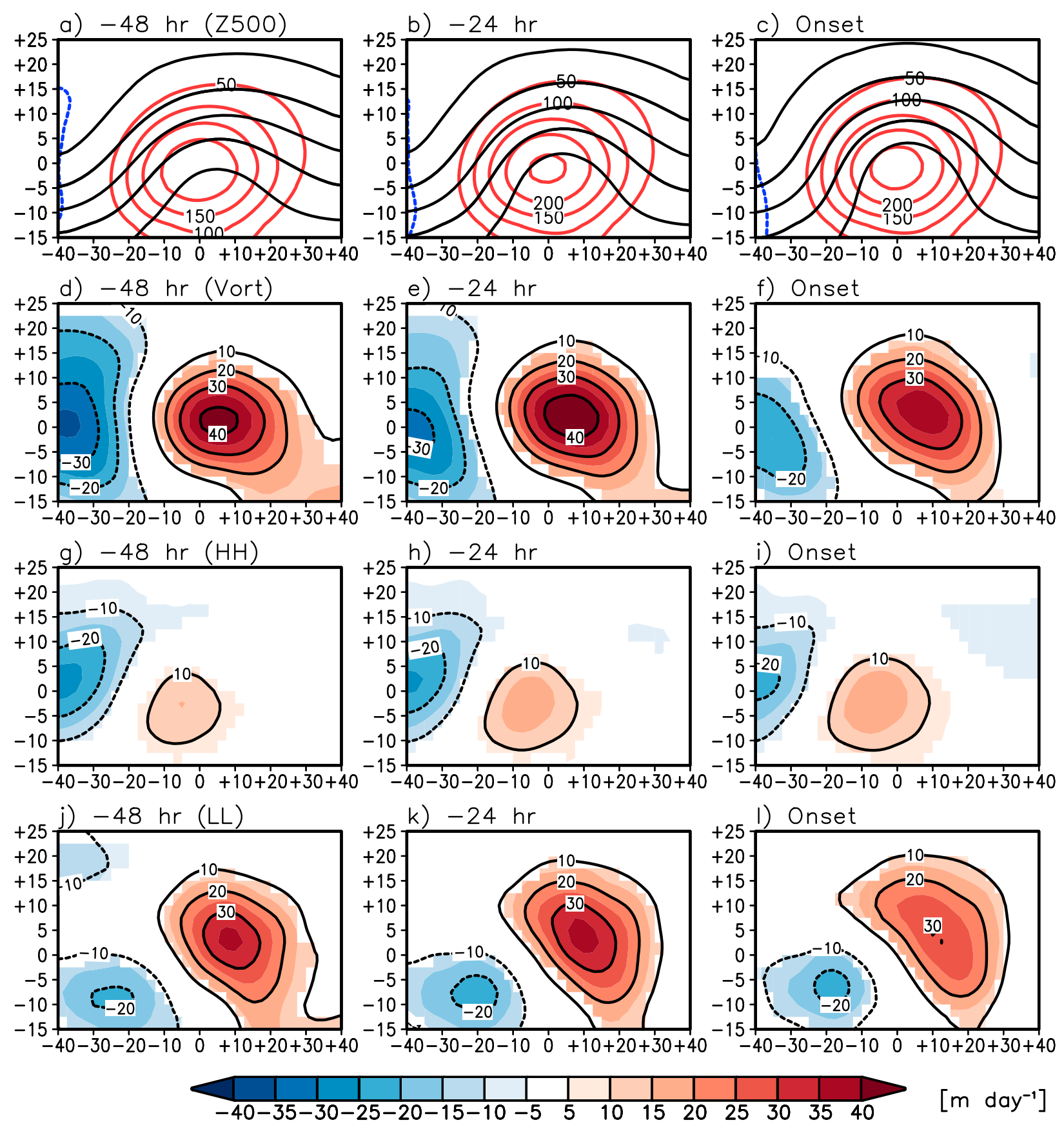

FIG. 11. Temporal evolution of (a)-(c) low-pass-filtered 500-hPa geopotential height (black contours; 100-m intervals) and corresponding anomalies (color contours; 50-m intervals) before the onset of NP blocking highs in winter. The tendency forced by (d)-(f) lowpass-filtered total vorticity fluxes, (g)-(i) high-frequency vorticity fluxes (low-pass-filtered HH), and (j)-(l) low-frequency vorticity fluxes (low-pass-filtered LL). All values are shown in relative longitude-latitude coordinates with respect to the low-pass-filtered blocking anomaly centers. Zero lines are omitted. Statistically significant values at the $95 \%$ confidence level are shaded.

It is plausible that the low-frequency background flow is influenced by subseasonal or interannual NP circulation variability, partly associated with the dominant modes of variability such as El Niño-Southern Oscillation, the Madden-Julian oscillation, and the Pacific-North America teleconnection. These modes of variability are known to affect the blocking frequency (Renwick and Wallace 1996; Croci-Maspoli et al. 2007; Henderson et al. 2016; Martineau et al. 2017) and such influence could manifest itself through cross-frequency vorticity fluxes. 
Further analysis of their possible influence, which would provide a better understanding of how changes in the basic state affect the blocking frequency, is warranted.

It may be valuable to apply the analysis presented in this study to NP blockings in climate models to assess model deficiencies (Anstey et al. 2013; Dunn-Sigouin and Son 2013; Davini and D'Andrea 2016; Davini et al. 2017). A preliminary analysis of a long-term climate model simulation suggests that although the spatiotemporal distribution of simulated blocking frequency is comparable to that of observations, the formation mechanism could be somewhat different. The details will be reported in a future study.

This study focuses on the rapid development of blocking, which is known to be an important source of errors in the blocking prediction in medium-range weather forecasts (Tibaldi and Molteni 1990; Matsueda 2011). Thus, our findings may also help to evaluated and improve the blocking prediction in operational numerical weather forecasts.

Acknowledgments. Support for the Jaeyoung Hwang and Seok-Woo Son was provided by the National Research Foundation of Korea (NRF) grant funded by the Korea government (Ministry of Science and ICT) (2017R1E1A1A01074889 and NRF-2018R1A5A1024958). Patrick Martineau acknowledges support as an international research fellow of the Japan Society for the Promotion of Science (P17029) and support by MEXT through the ArCS Project.

\section{APPENDIX}

\section{Rossby Wave Breaking Detection}

The detection of wave breaking $(B)$ is based on the reversal of the meridional gradient of potential temperature on the 2-PVU surface. The potential temperature $(\theta)$ gradient is evaluated with

$$
B(\lambda, \varphi)=\overline{\theta^{n}}(\lambda, \varphi)-\overline{\theta^{s}}(\lambda, \varphi),
$$

where $\overline{\theta^{n}}(\lambda, \varphi)=2 / \Delta \varphi \int_{\varphi_{o}}^{\varphi_{o}+15^{\circ}} \hat{\theta}(\lambda, \varphi) d \varphi$ and $\overline{\theta^{s}}(\lambda, \varphi)=$ $2 / \Delta \varphi \int_{\varphi_{0}-15^{\circ}}^{\varphi_{o}} \hat{\theta}(\lambda, \varphi) d \varphi$.

It is noted that $\overline{\theta^{n}}(\lambda, \varphi)$ is the potential temperature integrated $15^{\circ}$ to the north of a reference latitude $\varphi_{o}$. Likewise, $\overline{\theta^{s}}(\lambda, \varphi)$ is the potential temperature integrated $15^{\circ}$ to the south of the same reference latitude. $\Delta \varphi$ is defined as $30^{\circ}$. The hat operator denotes a running average over a $15^{\circ}$ longitude band. The $B(\lambda, \varphi)$ is evaluated for $\varphi_{o}$ within $40^{\circ}-70^{\circ} \mathrm{N}$ and at each longitude $\lambda$. The direction of wave breaking (DB) is then evaluated as follows:

$$
\begin{aligned}
\operatorname{DB}(\lambda, \varphi) & =\bar{\theta}(\lambda-\Delta \lambda, \varphi)-\bar{\theta}(\lambda+\Delta \lambda, \varphi), \\
\bar{\theta}(\lambda, \varphi) & =\frac{\overline{\theta^{n}}(\lambda, \varphi)+\overline{\theta^{s}}(\lambda, \varphi)}{2} .
\end{aligned}
$$

A $\Delta \lambda$ of $2.5^{\circ}$ is used to compute $\operatorname{DB}(\lambda, \varphi)$. The values of $B(\lambda, \varphi)$ and $\mathrm{DB}(\lambda, \varphi)$ are computed over a period of $12 \mathrm{~h}$ centered on the blocking onset. Blocking highs then can be classified into the three types of RWB (Masato et al. 2013):

Cyclonic RWB: $B(\lambda, \varphi)>0$ and $\operatorname{DB}(\lambda, \varphi)<0$, Anticyclonic RWB: $B(\lambda, \varphi)>0$ and $\operatorname{DB}(\lambda, \varphi)>0$, Non-RWB: $B(\lambda, \varphi)<0$ everywhere.

These criteria are assessed over the longitude band from $10^{\circ}$ west to $10^{\circ}$ east of blocking anomaly. Note that if two types of RWB (anticyclonic and cyclonic RWB) are found in the vicinity of the detected blocking, the type of RWB is assessed with the DB index upstream of the blocking.

\section{REFERENCES}

Alberta, T. L., S. J. Colucci, and J. C. Davenport, 1991: Rapid 500mb cyclogenesis and anticyclogenesis. Mon. Wea. Rev., 119, 1186-1204, https://doi.org/10.1175/1520-0493(1991)119<1186: RMCAA $>2.0 . \mathrm{CO} ; 2$.

Altenhoff, A. M., O. Martius, M. Croci-Maspoli, C. Schwierz, and H. C. Davies, 2008: Linkage of atmospheric blocks and synopticscale Rossby waves: A climatological analysis. Tellus, $\mathbf{6 0 A}$, 1053-1063, https://doi.org/10.1111/j.1600-0870.2008.00354.x.

Anstey, J. A., and Coauthors, 2013: Multi-model analysis of Northern Hemisphere winter blocking: Model biases and the role of resolution. J. Geophys. Res. Atmos., 118, 3956-3971, https://doi.org/10.1002/jgrd.50231.

Barriopedro, D., R. Garcia-Herrera, A. Lupo, and E. Hernandez, 2006: A climatology of Northern Hemisphere blocking. J. Climate, 19, 1042-1063, https://doi.org/10.1175/JCLI3678.1.

Berggren, R., B. Bolin, and C.-G. Rossby, 1949: An aerological study of zonal motion, its perturbations and break-down. Tellus, 1 (2), 14-37, https://doi.org/10.3402/tellusa.v1i2.8501.

Black, E., M. Blackburn, G. Harrison, and J. Methven, 2004: Factors contributing to the summer 2003 European heat wave. Weather, 59, 217-223, https://doi.org/10.1256/wea.74.04.

Cash, B. A., and S. Lee, 2000: Dynamical processes of block evolution. J. Atmos. Sci., 57, 3202-3218, https://doi.org/10.1175/ 1520-0469(2000)057<3202:DPOBE>2.0.CO;2.

Colucci, S. J., 1985: Explosive cyclogenesis and large-scale circulation changes: Implications for atmospheric blocking. J. Atmos. Sci., 42, 2701-2717, https://doi.org/10.1175/1520-0469(1985)042<2701: ECALSC $>2.0 . \mathrm{CO} ; 2$.

_ 1987: Comparative diagnosis of blocking versus nonblocking planetary-scale circulation changes during synoptic-scale cyclogenesis. J. Atmos. Sci., 44, 124-139, https://doi.org/ 10.1175/1520-0469(1987)044<0124:CDOBVN>2.0.CO;2.

, 2001: Planetary-scale preconditioning for the onset of blocking. J. Atmos. Sci., 58, 933-942, https://doi.org/10.1175/ 1520-0469(2001)058<0933:PSPFTO > 2.0.CO;2. 
Croci-Maspoli, M., C. Schwierz, and H. C. Davies, 2007: Atmospheric blocking: Space-time links to the NAO and PNA. Climate Dyn., 29, 713-725, https://doi.org/10.1007/s00382-007-0259-4.

Czernecki, B., M. Półrolniczak, L. Kolendowicz, M. Marosz, S. Kendzierski, and N. Pilguj, 2017: Influence of the atmospheric conditions on $\mathrm{PM}_{10}$ concentrations in Poznań, Poland. J. Atmos. Chem., 74, 115-139, https://doi.org/10.1007/s10874016-9345-5.

Davini, P., and F. D'Andrea, 2016: Northern Hemisphere atmospheric blocking representation in global climate models: Twenty years of improvements? J. Climate, 29, 8823-8840, https://doi.org/10.1175/JCLI-D-16-0242.1.

— , S. Corti, F. D'Andrea, G. Rivière, and J. von Hardenberg, 2017: Improved winter European atmospheric blocking frequencies in high-resolution global climate simulations. J. $A d v$. Model. Earth Syst., 9, 2615-2634, https://doi.org/10.1002/ 2017MS001082.

Dee, D., and Coauthors, 2011: The ERA-Interim reanalysis: Configuration and performance of the data assimilation system. Quart. J. Roy. Meteor. Soc., 137, 553-597, https://doi.org/ 10.1002/qj.828.

Dole, R. M., 1986a: Persistent anomalies of the extratropical Northern Hemisphere wintertime circulation: Structure. Mon. Wea. Rev., 114, 178-207, https://doi.org/10.1175/15200493(1986)114<0178:PAOTEN>2.0.CO;2.

_- 1986b: The life cycles of persistent anomalies and blocking over the North Pacific. Advances in Geophysics, Vol. 29, Academic Press, 31-69, https://doi.org/10.1016/ S0065-2687(08)60034-5.

__ 1989: Life cycles of persistent anomalies. Part I: Evolution of $500 \mathrm{mb}$ height fields. Mon. Wea. Rev., 117, 177-211, https://doi.org/10.1175/1520-0493(1989)117<0177:LCOPAP> 2.0.CO;2.

— , and N. D. Gordon, 1983: Persistent anomalies of the extratropical Northern Hemisphere wintertime circulation: Geographical distribution and regional persistence characteristics. Mon. Wea. Rev., 111, 1567-1586, https://doi.org/10.1175/1520-0493(1983) $111<1567$ :PAOTEN $>2.0 . \mathrm{CO} ; 2$.

- and Coauthors, 2011: Was there a basis for anticipating the 2010 Russian heat wave? Geophys. Res. Lett., 38, L06702, https://doi.org/10.1029/2010GL046582.

Drouard, M., and T. Woollings, 2018: Contrasting mechanisms of summer blocking over western Eurasia. Geophys. Res. Lett., 45, 12 040-12 048, https://doi.org/10.1029/2018GL079894.

Dunn-Sigouin, E., and S.-W. Son, 2013: Northern Hemisphere blocking frequency and duration in the CMIP5 models. J. Geophys. Res. Atmos., 118, 1179-1188, https://doi.org/ 10.1002/jgrd.50143.

,-- , and H. Lin, 2013: Evaluation of Northern Hemisphere blocking climatology in the Global Environment Multiscale model. Mon. Wea. Rev., 141, 707-727, https://doi.org/10.1175/ MWR-D-12-00134.1.

Efron, B., and R. J. Tibshirani, 1993: An Introduction to the Bootstrap. Stat. Appl. Probab. Monogr., Vol. 57, Chapman and Hall/CRC, 456 pp.

Gall, R., R. Blakeslee, and R. C. J. Sommerville, 1979: Cyclonescale forcing of ultralong waves. J. Atmos. Sci., 36, 1692-1698, https://doi.org/10.1175/1520-0469(1979)036<1692:csfouw $>$ 2.0.co;2.

Gangoiti, G., and Coauthors, 2002: Regional transport of pollutants over the Bay of Biscay: Analysis of an ozone episode under a blocking anticyclone in west-central Europe. Atmos. Environ., 36, 1349-1361, https://doi.org/10.1016/S1352-2310(01)00536-2.
Henderson, S. A., E. D. Maloney, and E. A. Barnes, 2016: The influence of the Madden-Julian oscillation on Northern Hemisphere winter blocking. J. Climate, 29, 4597-4616, https://doi.org/10.1175/JCLI-D-15-0502.1.

Holopainen, E., and C. Fortelius, 1987: High-frequency transient eddies and blocking. J. Atmos. Sci., 44, 1632-1645, https://doi.org/10.1175/1520-0469(1987)044<1632:HFTEAB > 2.0.CO;2.

Hong, C.-C., H.-H. Hsu, N.-H. Lin, and H. Chiu, 2011: Roles of European blocking and tropical-extratropical interaction in the 2010 Pakistan flooding. Geophys. Res. Lett., 38, L13806, https://doi.org/10.1029/2011GL047583.

Illari, L., 1984: A diagnostic study of the potential vorticity in a warm blocking anticyclone. J. Atmos. Sci., 41, 3518-3526, https://doi.org/ 10.1175/1520-0469(1984)041<3518:ADSOTP>2.0.CO;2.

Jensen, A. D., 2015: A dynamic analysis of a record breaking winter season blocking event. Adv. Meteor., 2015, 634896, https:// doi.org/10.1155/2015/634896.

Lau, N.-C., and E. O. Holopainen, 1984: Transient eddy forcing of the time-mean flow as identified by geopotential tendencies. J. Atmos. Sci., 41, 313-328, https://doi.org/10.1175/15200469(1984)041<0313:TEFOTT > 2.0.CO;2.

Lau, W. K. M., and K.-M. Kim, 2012: The 2010 Pakistan flood and Russian heat wave: Teleconnection of hydrometeorological extremes. J. Hydrometeor., 13, 392-403, https://doi.org/ 10.1175/JHM-D-11-016.1.

Luo, D., 2000: Planetary-scale baroclinic envelope Rossby solitons in a two-layer model and their interaction with synoptic-scale eddies. Dyn. Atmos. Oceans, 32, 27-74, https://doi.org/10.1016/ S0377-0265(99)00018-4.

Lupo, A. R., and P. J. Smith, 1995: Planetary and synoptic-scale interactions during the life cycle of a mid-latitude blocking anticyclone over the North Atlantic. Tellus, 47A, 575-596, https://doi.org/10.3402/tellusa.v47i5.11549.

Ma, S., and C. Zhu, 2019: Extreme cold wave over East Asia in January 2016: A possible response to the larger internal atmospheric variability induced by Arctic warming. J. Climate, 32, 1203-1216, https://doi.org/10.1175/JCLI-D-18-0234.1.

Martineau, P., G. Chen, and A. D. Burrows, 2017: Wave events: Climatology, trends, and relationship to Northern Hemisphere winter blocking and weather extremes. J. Climate, 30, 5675-5697, https://doi.org/10.1175/JCLI-D-16-0692.1.

Masato, G., B. J. Hoskins, and T. J. Woollings, 2012: Wave-breaking characteristics of midlatitude blocking. Quart. J. Roy. Meteor. Soc., 138, 1285-1296, https://doi.org/10.1002/qj.990.

,-- , and,- 2013 : Wave-breaking characteristics of Northern Hemisphere winter blocking: A two-dimensional approach. J. Climate, 26, 4535-4549, https://doi.org/10.1175/ JCLI-D-12-00240.1.

Matsueda, M., 2011: Predictability of Euro-Russian blocking in summer of 2010. Geophys. Res. Lett., 38, L06801, https://doi.org/ 10.1029/2010GL046557.

Mullen, S. L., 1987: Transient eddy forcing of blocking flow. J. Atmos. Sci., 44, 3-22, https://doi.org/10.1175/1520-0469(1987)044<0003: TEFOBF $>2.0 . \mathrm{CO} ; 2$.

Nakamura, H., and J. M. Wallace, 1993: Synoptic behavior of baroclinic eddies during blocking onsets. Mon. Wea. Rev., 121, 1892-1903, https://doi.org/10.1175/1520-0493(1993)121<1892: SBOBED $>2.0 . \mathrm{CO} ; 2$

, and T. Fukamachi, 2004: Evolution and dynamics of summertime blocking over the Far East and the associated surface Okhotsk high. Quart. J. Roy. Meteor. Soc., 130, 1213-1233, https://doi.org/10.1256/qj.03.101. 
__ M. Nakamura, and J. L. Anderson, 1997: The role of highand low-frequency dynamics and blocking formation. Mon. Wea. Rev., 125, 2074-2093, https://doi.org/10.1175/15200493(1997)125<2074:TROHAL > 2.0.CO;2.

Nakamura, N., and C. S. Y. Huang, 2018: Atmospheric blocking as a traffic jam in the jet stream. Science, 361, 42-47, https:// doi.org/10.1126/science.aat0721.

Park, T.-W., C.-H. Ho, and S. Yang, 2011: Relationship between the Arctic oscillation and cold surges over East Asia. J. Climate, 24, 68-83, https://doi.org/10.1175/2010JCLI3529.1.

Pfahl, S., C. Schwierz, M. Croci-Maspoli, C. M. Grams, and H. Wernli, 2015: Importance of latent heat release in ascending air streams for atmospheric blocking. Nat. Geosci., 8 , 610-614, https://doi.org/10.1038/ngeo2487.

Reinhold, B. B., and R. T. Pierrehumbert, 1982: Dynamics of weather regimes: Quasi-stationary waves and blocking. Mon. Wea. Rev., 110, 1105-1145, https://doi.org/10.1175/ 1520-0493(1982)110<1105:DOWRQS > 2.0.CO;2.

Renwick, J. A., and J. M. Wallace, 1996: Relationships between North Pacific wintertime blocking, El Niño, and the PNA pattern. Mon. Wea. Rev., 124, 2071-2076, https://doi.org/ 10.1175/1520-0493(1996)124<2071:RBNPWB>2.0.CO;2.

Rex, D. F., 1950: Blocking action in the middle troposphere and its effect upon regional climate. I. An aerological study of blocking action. Tellus, 2, 196-211, https://doi.org/10.1111/ j.2153-3490.1950.tb00331.x.

Sausen, R., W. Konig, and F. Sielman, 1995: Analysis of blocking events from observations and ECHAM model simulations. Tellus, 47A, 421-438, https://doi.org/10.3402/tellusa.v47i4.11526.

Schaller, N., J. Sillmann, J. Anstey, E. M. Fischer, C. M. Grams, and S. Russo, 2018: Influence of blocking on northern European and western Russian heatwaves in large climate model ensembles. Environ. Res. Lett., 13, 054015, https://doi.org/10.1088/ 1748-9326/aaba55.

Schneidereit, A., S. Schubert, P. Vargin, F. Lunkeit, X. Zhu, D. H. W. Peters, and K. Fraedrich, 2012: Large-scale flow and the longlasting blocking high over Russia: Summer 2010. Mon. Wea. Rev., 140, 2967-2981, https://doi.org/10.1175/MWR-D-11-00249.1.
Shutts, G. J., 1983: The propagation of eddies in diffluent jetstreams: Eddy vorticity forcing of 'blocking' flow fields. Quart. J. Roy. Meteor. Soc., 109, 737-761, https://doi.org/10.1002/ qj. 49710946204.

Takaya, K., and H. Nakamura, 2005a: Mechanisms of intraseasonal amplification of the cold Siberian high. J. Atmos. Sci., 62, 4423-4440, https://doi.org/10.1175/JAS3629.1.

_ and _ 2005b: Geographical dependence of upper-level blocking formation associated with intraseasonal amplification of the Siberian high. J. Atmos. Sci., 62, 4441-4449, https:// doi.org/10.1175/JAS3628.1.

Tibaldi, S., and F. Molteni, 1990: On the operational predictability of blocking. Tellus, 42A, 343-365, https://doi.org/10.3402/ tellusa.v42i3.11882.

Tracton, M. S., 1990: Predictability and its relationship to scale interaction processes in blocking. Mon. Wea. Rev., 118, 1666-1695, https://doi.org/10.1175/1520-0493(1990)118<1666:PAIRTS > 2.0.CO;2.

Trigo, R. M., I. F. Trigo, C. C. DaCamara, and T. J. Osborn, 2004: Climate impact of the European winter blocking episodes from the NCEP/NCAR reanalyses. Climate Dyn., 23, 17-28, https://doi.org/10.1007/s00382-004-0410-4.

Tsou, C.-H., and P. J. Smith, 1990: The role of synoptic/planetary-scale interactions during the development of a blocking anticyclone. Tellus, 42A, 174-193, https://doi.org/10.3402/tellusa.v42i1.11869.

Woollings, T., and Coauthors, 2018: Blocking and its response to climate change. Curr. Climate Change Rep., 4, 287-300, https:// doi.org/10.1007/s40641-018-0108-z.

Yamada, T. J., D. Takeuchi, M. A. Farukh, and Y. Kitano, 2016: Climatological characteristics of heavy rainfall in northern Pakistan and atmospheric blocking over western Russia. J. Climate, 29, 7743-7754, https://doi.org/10.1175/JCLI-D15-0445.1.

Yeh, S.-W., Y.-J. Won, J.-S. Hong, K.-J. Lee, M. Kwon, K.-H. Seo, and Y.-G. Ham, 2018: The record-breaking heat wave in 2016 over South Korea and its physical mechanism. Mon. Wea. Rev., 146, 1463-1474, https://doi.org/10.1175/MWRD-17-0205.1. 